\title{
Doctors' Attitude and Willingness to Use Electronic Medical Records at the Lagos University Teaching Hospital, Lagos, Nigeria.
}

\author{
Onigbogi $0.0^{1}$, Poluyi A.O², Poluyi C.O3 , Onigbogi M.O4
}

1. Department of Community Health and Primary Care, College of Medicine, University of Lagos, Idi Araba, Lagos, Nigeria.

2. College of Medicine, University of Lagos, Idi Araba, Lagos

3. Covenant University Medical Center, Ota, Nigeria.

4. Department of Epidemiology, Human Genetics and Environmental Sciences, University of Texas Health Sciences at Houston, Texas, U.S.A.

\begin{abstract}
Background: There have been few studies conducted on Electronic Medical Records (EMR) among medical doctors who practice in resource limited settings. This study aimed to assess the attitude to and willingness of medical doctors at the Lagos University Teaching Hospital to use EMR and to identify the factors that are associated with the willingness to use EMR.

Methods: A stratified sampling method was used to select medical doctors to participate in the study according to their experience and professional cadre. A pretested self-administered questionnaire was used to collect data which were entered and analyzed using the Epi-info version 7 software. Statistically significant associations were tested using the chi-square and fishers exact tests.

Results: There were 202 participants in the study. All (100\%) had good attitude towards EMR. Nearly all of them (96.54\%) were willing to use EMR. There was no significant association between age, gender and willingness to use EMR. However, there was a statistically significant association with work duration and IT skills $(p<0.05)$.

Conclusion: Work duration and IT skills are significant factors in determining the willingness to use EMR. There is therefore a need to include IT skills acquisition in medical training so as to increase the chance of use of EMR.

Correspondence: lanreonigbogi@yahoo.com

Keywords: Electronic Medical Records (EMR), Attitude, Willingness, IT, Skills, Doctors

DOI: $10.5210 /$ ojphi.v10i2.8416

Copyright (C2018 the author(s)

This is an Open Access article. Authors own copyright of their articles appearing in the Online Journal of Public Health Informatics. Readers may copy articles without permission of the copyright owner(s), as long as the author and OJPHI are acknowledged in the copy and the copy is used for educational, not-for-profit purposes.
\end{abstract}




\section{Introduction}

The use of electronic medical records (EMR) has been proven to improve the quality of health care worldwide by increasing productivity, reducing workload, minimizing costs and creating a sustainable link between health care providers [1]. This has contributed to its increasing adoption by healthcare organizations globally including Nigeria, a country where electronic medical records have been prioritized by its government [2,3]. In some parts of the country, electronic medical records have been implemented however, published research on the pre-implementation stages is scarce [4].

The immediate step after a decision to transition to EMRs, is addressing the possible barriers to its successful implementation [5]. Previous studies have categorized a number of these barriers into functional, organizational, technical, training, political, ethical and financial; the most common of which is related to the unwillingness of its users to accept the transition. This has contributed to the failure rates of many EMR installations [2]. It is therefore necessary to have a roadmap before adopting EMRs to prevent wastage of resources.

Most studies are focused on the implementation and post implementation stages of electronic medical records and have neglected the need neglect the need for an initial assessment of the potential users of these systems which in this case, are the doctors $[1,6,7]$.

\section{Materials and Methods}

This study aimed to assess the attitude towards and willingness of doctors at the Lagos University Teaching Hospital to the use of electronic medical records. It also aimed to identify the factors that are significantly associated with the willingness to use electronic medical records.

\section{Study design}

This was a cross sectional descriptive study to determine the attitude to, and willingness to the use of electronic medical records by medical doctors at the Lagos University Teaching Hospital.

\section{Setting}

Our study was conducted at the Lagos University Teaching Hospital (LUTH), founded in 1962. It is the foremost referral hospital in Lagos metropolis located in Idi-Araba, Mushin LGA of Lagos State, South-West Nigeria. The hospital is the largest teaching hospital in Nigeria with 761 beds and records approximately 10,000 patient attendances in a month [8]. The hospital has thirteen clinical departments; about one hundred and sixty-eight honorary consultants, forty seven consultants, one hundred and ninety senior registrars, two hundred and eighty nine registrars and about two hundred house officers yearly, giving a total of 894 doctors across the thirteen clinical departments [9].

\section{Selection of respondents}

A stratified sampling method was used to select 202 doctors at the Lagos University Teaching Hospital, Idi-Araba, Lagos by dividing them according to their cadre, i.e house officers, resident doctors and senior resident doctors. Four clinical departments were assessed; medicine, pediatrics, obstetrics and gynecology, and surgery. 


\section{Data collection}

The data was collected through a self-administered questionnaire and was pretested among 20 medical doctors in Lagos State University Teaching Hospital (LASUTH). The outcome was used in structuring the questionnaire to avoid ambiguity and include likely options. The questionnaire was stratified into sections on socio-demographic information, attitude and willingness to use electronic medical records respectively.

\section{Socio- demographic information}

This contained 7 items which included questions on age as at last birthday, sex: which was recorded as male or female or as observed by the researcher. The marital status refers to discrete options describing a person's relationship with a significant other and was recorded by the respondent as single, married or separated. The religion of the respondents was classified as Christianity, Islam, Traditional or others. A question was asked on the number of years which respondents had worked at the hospital. Respondents were also asked to rate their Information Technology (IT) skills from 'bad' to 'very good'.

\section{Respondent's attitude towards the use of Electronic Medical Records}

This section contained 14 questions adapted from a study conducted at the Hormozgan Medical Sciences University, Iran [1]. A 5-point Likert scale was used to score the responses ranging from "agree" to "strongly disagree". Thirteen of the questions were positive and respondents that gave positive answers got the appropriate marks for the scale. The question that 'electronic medical records are not feasible in small practices' was the only negative question and respondents that gave a negative answer to it were correct. The maximum score obtainable was 70 marks while the minimum score obtainable was 14 marks. A score of $42(50 \%)$ and above suggested good attitude while a score of less than 42 , suggested poor attitude.

\section{Respondent's willingness to use EMRs}

Six questions were asked in this section and respondents were asked to indicate either 'Yes' or 'No'. Five of these questions were scored. The maximum score obtainable was 5 marks. A score of 3 marks and above out of 5 marks suggested willingness while a score of less than 3 marks suggested unwillingness..

\section{Data analysis}

Data collected were immediately coded, verified and analyzed. Only fully answered questionnaires were analyzed. Epi-Info, version 7 was used for this. Proportions, means and frequencies were calculated and presented as tables. Chi-square was used to test for associations between age, gender, work duration in LUTH, IT skills and willingness to use electronic medical records. Association was said to be statistically significant, if $p$ value was $\leq 0.05$.

Ethical consideration was gotten from the Health Research and Ethics Committee of Lagos University Teaching Hospital. Participants were informed of the purpose of the study and oral consent was obtained from each of the participants before administering the questionnaires. 


\section{Results}

\section{Socio demographic characteristics}

The mean age of the respondents was 18.74 \pm 1.88 . About half of them were within the age range of 30-39 years (See Table 1). Of the respondents, 107 (52.97\%) were males while 95(47.03\%) were females (Table 1). More than half of them were married 113(55.94\%). One hundred and eight $(53.47 \%)$ of the study participants had worked at the hospital for less than 12 months while less than half of them 94(46.55\%) had worked for over 12 months, (Table 1). Interestingly, 104(51.49\%) and $41(20.30 \%)$ of the respondents rated their IT skills as 'good' and 'very good' respectively.

\section{Awareness and attitude towards EMRs}

All the respondents $202(100 \%)$ had heard the term EMR before. More than two-thirds (71.78\%) of the respondents who had heard about EMRs strongly agreed that it would improve quality of care and reduce medical errors. Majority of the study participants 197(97.53\%) said it would improve quality of practice. About half of the respondents 106(52.03\%) strongly agreed that EMRs would increase patients' satisfaction with the health care provider. Nearly all of them $187(92.57 \%)$ were of the opinion that the benefits of EMRs outweigh its cost. More than half 123(60.89\%) of the respondents were certain that EMRs would decrease the burden on physicians.

Regarding the perceived barriers to the implementation of EMRs, more than three quarters $178(88.12 \%)$ of the respondents said that a major barrier to the implementation of electronic medical records is the structural and administrative rigidity of organizations in accommodating the changes involved. Less than half of the respondents 99(49.01\%) strongly agreed that EMRs cannot be used without the availability of skilled resources and provision of support. About 130(64.36\%) of the respondents strongly agreed that proper training would be required before the implementation of EMRs and were willing $182(90.10 \%)$ to devote time to undergo the training required for its implementation. Majority 199(98.51\%) were of the opinion that it should be implemented in LUTH.

\section{Willingness to use electronic medical records}

More than two thirds $160(79.21 \%)$ of the respondents said they were willing to purchase personal laptops/computers to get familiar with the EMR system. Nearly all 195(96.53\%) of them said they were willing to use EMRs if properly trained and if the technical infrastructures in LUTH are made available 198(98.02\%).

\section{Factors associated with the willingness to use electronic medical records}

In this study, majority of the respondents in the age groups 20-29 and 30-39 were willing to use electronic medical record, $(94.8 \%, 97.12 \%)$ respectively. All the respondents between the ages of 40-49 were willing to use electronic medical records. This association however, was not statistically significant. $(\mathrm{p}=0.527)$.

Even though more males were willing to use EMRs than females, majority of both sexes were willing to use EMRs $(97.20 \%, 95.79 \%)$. Gender however, was not said to be statistically significant with willingness to use. $(\mathrm{p}=0.707)$ 
Majority of the respondents who had worked for less than 1 year (97.22\%), from 1-2 years(93.33\%), 3-4 years(93.33\%), and 4-5 years(90.91\%) were willing to use electronic medical records. All the respondents that had worked for 2-3 years $(100 \%)$ and greater than 5 years $(100 \%)$ were willing to use electronic medical records. This association was found to be statistically significant $(\mathrm{p}=0.003)$.

Respondents with good IT skills were the most willing (95.12\%). All the respondents with bad IT skills were unwilling to use electronic medical records. (100\%) A statistical significance was found between respondents' IT skills and their willingness to use electronic medical records. $(\mathrm{p}=0.038)$.

Table 1: Socio-demographic characteristics of respondents $(n=202)$

\begin{tabular}{|c|c|c|}
\hline Variable & Frequency & Percentage $(\%)$ \\
\hline \multicolumn{3}{|c|}{ Age (in years) } \\
\hline $20-29$ & 77 & 38.11 \\
\hline $30-39$ & 104 & 51.49 \\
\hline $40-49$ & 21 & 10.40 \\
\hline \multicolumn{3}{|l|}{ Sex } \\
\hline Male & 107 & 52.97 \\
\hline Female & 95 & 47.03 \\
\hline \multicolumn{3}{|c|}{ Marital Status } \\
\hline Single & 87 & 43.07 \\
\hline Married & 113 & 55.94 \\
\hline Separated & 2 & 0.99 \\
\hline \multicolumn{3}{|l|}{ Religion } \\
\hline Christianity & 165 & 81.68 \\
\hline Islam & 37 & 18.32 \\
\hline \multicolumn{3}{|c|}{ Duration of Work (in years) } \\
\hline$\leq 1$ & 108 & 53.47 \\
\hline $1-2$ & 30 & 14.85 \\
\hline $2-3$ & 23 & 11.39 \\
\hline $3-4$ & 15 & 7.43 \\
\hline $4-5$ & 11 & 5.45 \\
\hline$\geq 5$ & 15 & 7.43 \\
\hline \multicolumn{3}{|c|}{ Rate your IT skills } \\
\hline Very Good & 41 & 20.30 \\
\hline Good & 104 & 51.49 \\
\hline Average & 56 & 27.72 \\
\hline Bad & 1 & 0.50 \\
\hline
\end{tabular}


Table 2: Awareness and attitude of respondents to the use of electronic medical records $(\mathbf{n}=\mathbf{2 0 2})$

\begin{tabular}{|c|c|c|c|c|c|}
\hline Statements & $\begin{array}{l}\text { Strongly } \\
\text { Agree } \\
(\%)\end{array}$ & $\begin{array}{l}\text { Agree } \\
(\%)\end{array}$ & $\begin{array}{l}\text { Neutral } \\
(\%)\end{array}$ & $\begin{array}{l}\text { Disagree } \\
(\%)\end{array}$ & $\begin{array}{l}\text { Strongly } \\
\text { Disagree } \\
(\%)\end{array}$ \\
\hline $\begin{array}{l}\text { EMRs would improve quality of care } \\
\text { and reduce errors }\end{array}$ & $145(71.78)$ & $52(25.74)$ & $4(1.98)$ & $1(0.50)$ & $0(0.00)$ \\
\hline $\begin{array}{l}\text { EMRs would improve quality of } \\
\text { work life }\end{array}$ & $140(69.31)$ & $57(28.22)$ & $5(2.48)$ & $0(0.00)$ & $0(0.00)$ \\
\hline $\begin{array}{l}\text { EMRs would increase patients' } \\
\text { satisfaction }\end{array}$ & $106(52.48)$ & $72(35.64)$ & $22(10.89)$ & $2(0.99)$ & $0(0.00)$ \\
\hline The benefits would outweigh the cost & $100(49.50)$ & $87(43.07)$ & $12(5.94)$ & $2(0.99)$ & $1(0.50)$ \\
\hline $\begin{array}{l}\text { EMR would decrease burden on } \\
\text { physicians }\end{array}$ & $123(60.89)$ & $60(29.70)$ & $13(6.44)$ & $5(2.48)$ & $1(0.50)$ \\
\hline $\begin{array}{l}\text { EMRs would make patients' data } \\
\text { accessible }\end{array}$ & $152(75.25)$ & $48(23.76)$ & 2(0.99) & $0(0.00)$ & $0(0.00)$ \\
\hline $\begin{array}{l}\text { EMRs would increase practice } \\
\text { productivity }\end{array}$ & $112(55.45)$ & $59(29.21)$ & $24(11.88)$ & $5(2.48)$ & $2(0.99)$ \\
\hline $\begin{array}{l}\text { EMRs used in small practices is not } \\
\text { feasible because of high capital } \\
\text { investment and risk of insufficient } \\
\text { return }\end{array}$ & $26(12.87)$ & $53(26.24)$ & $33(16.34)$ & $73(36.14)$ & $17(8.42)$ \\
\hline $\begin{array}{l}\text { A possible barrier to the use of } \\
\text { EMRs is administrative rigidity }\end{array}$ & $102(50.50)$ & $76(37.62)$ & $11(5.45)$ & $13(6.44)$ & $0(0.00)$ \\
\hline $\begin{array}{l}\text { EMRs cannot be used without the } \\
\text { availability of skilled resources and } \\
\text { support }\end{array}$ & $99(49.01)$ & $84(41.58)$ & $7(3.47)$ & $10(4.95)$ & $2(0.99)$ \\
\hline $\begin{array}{l}\text { Users resistance to EMRs due to fear } \\
\text { of the negative consequences of the } \\
\text { technology is a barrier }\end{array}$ & $71(35.15)$ & $80(39.60)$ & $29(14.36)$ & $19(9.41)$ & $3(1.49)$ \\
\hline Proper training would be required & $130(64.36)$ & $68(33.66)$ & $2(0.99)$ & $2(0.99)$ & $0(0.00)$ \\
\hline $\begin{array}{l}\text { I would devote time to undergo } \\
\text { training for its implementation }\end{array}$ & $95(47.03)$ & 87 (43.07) & $15(7.43)$ & $5(2.48)$ & $0(0.00)$ \\
\hline $\begin{array}{l}\text { An EMR system should be } \\
\text { implemented in LUTH }\end{array}$ & 149 (73.76) & $50(24.75)$ & $3(1.49)$ & $0(0.00)$ & $0(0.00)$ \\
\hline
\end{tabular}

Table 3: Willingness of respondents to use electronic medical records $(n=202)$

\begin{tabular}{lrr}
\hline Statements & Frequency & Percentage (\%) \\
\hline I would be willing to undergo computer training to enable my & 191 & 94.55 \\
usage of EMRs & 11 & 5.45 \\
Yes & &
\end{tabular}




\section{OJPHI}

\begin{tabular}{lrr}
\hline No & & \\
$\begin{array}{l}\text { I am willing to purchase a personal laptop/computer to } \\
\text { familiarize myself with the usage of EMRs }\end{array}$ & 160 & 79.21 \\
Yes & & 20.79 \\
No & 195 & 96.53 \\
I am willing to undergo trainings on EMRs \& its implementation & 7 & 3.47 \\
Yes & & \\
No & 195 & 96.53 \\
I would be willing to use EMRs if properly trained & 7 & 3.47 \\
Yes & & \\
No & 198 & 98.02 \\
I am willing to use EMRs if the technical infrastructures in LUTH & 4 & 1.98 \\
are made available & & \\
Yes & & \\
No & &
\end{tabular}

Table 4: Factors associated with the willingness of respondents to use electronic medical records $(n=202)$

\begin{tabular}{|c|c|c|c|c|c|}
\hline Variable & Group & Willingness & $(\%)$ & $\mathbf{X}^{2}$ & P value \\
\hline & & Willing & Not willing & & \\
\hline \multirow[t]{3}{*}{ Age } & $20-29$ & 94.80 & 5.19 & 1.547 & $* 0.527$ \\
\hline & $30-39$ & 97.12 & 2.88 & & \\
\hline & $40-49$ & 100.00 & 0.00 & & \\
\hline \multirow[t]{2}{*}{ Gender } & Male & 97.20 & 2.80 & 0.298 & 0.707 \\
\hline & Female & 95.79 & 4.21 & & \\
\hline \multirow[t]{6}{*}{ Work duration in LUTH } & $\leq 1$ & 97.22 & 2.78 & 18.172 & $* 0.003$ \\
\hline & $1-2$ & 93.33 & 6.67 & & \\
\hline & $2-3$ & 100.00 & 0.00 & & \\
\hline & $3-4$ & 93.33 & 6.67 & & \\
\hline & $4-5$ & 90.91 & 9.09 & & \\
\hline & $\geq 5$ & 100.00 & 0.00 & & \\
\hline \multirow[t]{4}{*}{ IT skills } & Very Good & 95.12 & 4.88 & 7.759 & $* 0.038$ \\
\hline & Good & 99.04 & 0.96 & & \\
\hline & Average & 94.64 & 5.36 & & \\
\hline & $\mathrm{Bad}$ & 0.00 & 100.00 & & \\
\hline
\end{tabular}

*Fisher's exact used 


\section{Discussion}

Our study assessed the attitude of doctors at the Lagos University Teaching Hospital (LUTH) as well as their willingness to use electronic medical records. All the respondents $(100 \%)$ had heard about the term electronic medical records while majority of them, 182(90.10\%) expressed willingness to devote time for training in order to facilitate their use of EMRs. This finding is in contrast with a study conducted in Bandar Abbas, Iran where only $30 \%$ of the respondents said they would devote the time required for training on the use of EMRs [1]. This may be due to the fact that the degree of specialization in LUTH is higher than that which obtained in the setting for the Iranian study. The doctors in our study may have been motivated to have further training in EMR by virtue of the expectations of training position which they held during the period.

We can conclude from this study that the doctors at the Lagos University Teaching Hospital were excited about the prospects of an EMR installation as 191(94.6\%) of them were willing to undergo computer training to facilitate their use of EMRs. More than two thirds of the respondents $160(79.21 \%)$ were also willing to purchase personal laptops/computers for further training with $104(51.9 \%)$ of the respondents having very good IT skills. These findings are similar to a study in Norway were $72 \%$ of participants had good computer skills but contrary to the study conducted in the Saudi Arabia among 106 physicians where 21\% of participants had good IT experience [10]. This could be due to the unavailability of supporting infrastructure in those settings.

All the respondents in this study had a good attitude to the use of EMRs. This is similar to a study conducted in Kuwait, Eastern Arabia where the nurses generally had a positive attitude towards computerized health information systems. A study conducted in Ethiopia also showed that more than half of the respondents had good attitude. In Nigeria, a study among healthcare workers in Ekiti, also indicated that majority $(97.58 \%)$ of the doctors had positive attitude to the use of technology in healthcare [11-13].

Our study showed one hundred percent good attitude to the use of electronic medical records as well as high willingness to use electronic medical records at the Lagos University Teaching Hospital. This is similar to a study done in Iran where the overall readiness to use electronic medical records was $52 \%$ [1].

Majority of the respondents willing to use electronic medical records in this study were between 20 and 39 years old. In a similar study done in a semi-urban center in Nigeria, majority of the respondents who were willing were also young [13]. This shows that the younger a population is, the more willing they are to try new things.

There was a significant association between the years of experience and willingness to use electronic medical records as all (100\%) the respondents above 29 years were willing to use electronic medical records. This is also similar to a study conducted in Ido-Ekiti [13].

Several studies have indicated that there is a relationship between the level of IT skills and the willingness to use electronic medical records and this study was no exception. Respondents with very good IT skills were willing to use EMRs. Those with good IT skills were the most willing $(95.12 \%)$. All the respondents with bad IT skills were not willing to use electronic medical records $(100 \%)$. This is supported by the study in Riyadh and Jeddah's city where a significant relationship 
between the ease of use and self-efficacy was found [10]. In the study done in Ethiopia, $80 \%$ of them had good IT skills and were ready to use electronic medical records [14]. In a military hospital in Riyadh however, only $31.3 \%$ of the physicians were willing to use EMRs and the level of IT experience was low $(8.7 \%)$ [15].

In conclusion, our result shows that there is a very high positive attitude and willingness to use electronic medical records by the potential users of the system. It also identifies work duration and IT skills as significant factors in determining the willingness to use electronic medical records. A more comprehensive study can be done to assess the readiness of the Lagos University Teaching Hospital as a site for the installation of the system creating a clear path for the implementation of electronic medical records.

\section{Limitations}

Our findings should be interpreted with some caution due to certain limitations which we had. Our survey respondents consisted of interns and resident doctors only, a group comprising of persons who had clinical training appointments at the time of the study. The expectation of being IT-savvy associated with the training environment might have given rise to some bias in their responses to training-related questions. Secondly, the training-related infrastructure that is obtainable in teaching hospitals such as that used for the survey may be associated with bias for IT and the use of EMR. Thirdly, this study may have led to an over-estimation because it did not measure actual use but observed the willingness-to-use which may be exaggerated to demonstrate a leaning towards modern methods by the participants. This probability of over-estimation can be reduced in future surveys by conducting mini IT-capacity tests which may be a better reflection of abilities as compared with that which was reported by respondents.

\section{REFERENCES}

1. Lakbala P, Dindarloo K. 2014. Physicians' perception and attitude toward electronic medical record. Springerplus. 3, 63. PubMed https://doi.org/10.1186/2193-1801-3-63

2. Stone CP. Glimpse at EHR Implementation Around the World: The Lessons the US Can Learn. The Health Institute for E-Health Policy. May 2014. Available from http://www.ehealthpolicy.org/docs/A_Glimpse_at_EHR_Implementation_Around_the_World 1_ChrisStone.pdf (Accessed 14 ${ }^{\text {th }}$ January 2018).

3. Amosa B, Adepoju T, Hameed A, Fabiyi A, Olatunbosun E. 2016. Investigating electronic medical record system of selected healthcare institutions in Nigeria. IJARSET. 3(12), 3086-91.

4. Thompson A, Castle E, Lubeck P, Makarfi P. Experience implementing OpenMRS to support maternal and reproductive health in Northern Nigeria. InMedInfo 2010 (pp. 332-336).

5. WHO. (West Pacific Region). Electronic health records: manual for developing countries. Revised edition. Geneva: World Health Organisation 2006. Available at: http://apps.who.int/iris/bitstream/10665/207504/1/9290612177_eng.pdf (Accessed 30th June 2017) 
6. Jennett P, Jackson A, Healy T, Ho K, Kazanjian A, et al. 2003. A study of a rural community's readiness for telehealth. J Telemed Telecare. 9, 259-63. Accessed January $14^{\text {th }}, 2018$. doi:https://doi.org/10.1258/135763303769211265. PubMed

7. Demiris G, Oliver DP, Kruse RL, Wittenberg-Lyles E. 2013. Telemed J E Health. 19(4), 23540. Accessed January $14^{\text {th }}$, 2018. doi:https://doi.org/10.1089/tmj.2012.0185. PubMed

8. LUTH administrative department, Cadre of Doctors in Lagos University Teaching Hospital as at May, 2017.Personal communication. 18th August 2017.

9. Tierney WM, Achieng M, Baker E, Bell A, Biondich PG, et al. Experience implementing electronic health records in three East African countries. InMedInfo 2010; 20: 371-375. Avaialble at https://www.ncbi.nlm.nih.gov/pubmed/20841711 (Accessed 30 ${ }^{\text {th }}$ June 2017).

10. Khalifa M. 2013. Barriers to health information systems and electronic medical records implementation: a field study of Saudi Arabian hospitals. Procedia Comput Sci. 21, 335-42. https://doi.org/10.1016/j.procs.2013.09.044

11. Baron RJ, Fabens EL, Schiffman M, Wolf E. 2005. Electronic health records: just around the corner? or over the cliff? Ann Intern Med. 143(3), 222-26. https://www.ncbi.nlm.nih.gov/pubmed/16061920. Accessed June 30 ${ }^{\text {th }}$, 2017. PubMed https://doi.org/10.7326/0003-4819-143-3-200508020-00008

12. Malik MA, Khan HR. Understanding the implementation of an electronic hospital information system in a developing country: a case study from Pakistan. In Proceedings of the Third Australasian Workshop on Health Informatics and Knowledge Management. 2009;97:31-36.

13. Olufunmilayo A, Idowu A, Raji O, Gabriel E, Onigbogi O. 2017. Knowledge, attitude and willingness to use mHealth technology. Journal of Advances in Medicine and Medical Research. 22(8), 1-10. https://doi.org/10.9734/JAMMR/2017/33232

14. Biruk S, Yilma T, Andualem M, Tilahun B. 2014. Health professionals' readiness to implement electronic medical record system at three hospitals in Ethiopia: a cross sectional study. BMC Med Inform Decis Mak. 14(1), 115. Accessed June 28 ${ }^{\text {th }}, 2017$. doi:https://doi.org/10.1186/s12911-014-0115-5. PubMed

15. Mohamed BA, El-Naif M. 2005. Physicians', Nurses' and Patients'perception with hospital medical records at a military hospital in Riyadh, Saudi Arabia. J Family Community Med. 12(1), 49. https://www.ncbi.nlm.nih.gov/pmc/articles/PMC3410137/. Accessed July 1 ${ }^{\text {st }} 2017$. PubMed 